\title{
Oral health among 35-year-olds in Oslo, Norway. A summary of time trends 1973-2003
}

\author{
Rasa Skudutyte-Rysstad ${ }^{1}$, Harald M. Eriksen ${ }^{2}$ and Espen Bjertness ${ }^{3,4}$ \\ 1) Institute of Clinical Dentistry, Faculty of Dentistry, University of Oslo, Norway \\ 2) Institute of Clinical Dentistry, Faculty of Health Sciences, University of Tromsø, Norway \\ 3) Department of Community Medicine, Faculty of Medicine, University of Oslo, Norway \\ 4) Tibet University Medical College, Lhasa, Tibet, China \\ Correspondence: Rasa Skudutyte-Rysstad, Institute of Clinical Dentistry, Faculty of Dentistry, University of Oslo, \\ P.O. box 1109 Blindern, NO-0317 Oslo, Norway \\ E-mail: rasa.skudutyte-rysstad@odont.uio.no Telephone: +47 22852132
}

\begin{abstract}
Background: Oral health conditions have been investigated in 35-year-old Oslo citizens in four cross-sectional, age-specific epidemiological studies performed in 1973, 1984, 1993 and 2003. The main aim of the series of investigations was to monitor changes in oral health, including dental caries and endodontic and periodontal conditions. Data will give clues to what extent the documented improvements in oral health among children and adolescents also have been maintained into adulthood.

Methods: Random samples of 200-250 35-year-olds were selected from The Norwegian Bureau of Statistics database and invited to participate. They completed a self administered questionnaire and were examined clinically and radiographically. The attendance rate varied between $64 \%$ and $80 \%$.

Findings: The results presented are based on time-trend analyses. Caries prevalence, measured as the mean DMFS scores, was high and stable from 1973 (DMFS=68.2) to 1984 (DMFS=66.5), but decreased from 1984 (DMFS $=40.9$ ) to 2003 (DMFS=26.1), indicating a 62\% reduction in caries and treatment experience. During the whole period, the prevalence of root filled teeth and prevalence of apical periodontitis decreased, but no improvement from 1993 to 2003 could be demonstrated. Assessment of periodontal status showed that the proportion of persons with one or more periodontal pockets $\geq 6 \mathrm{~mm}$ decreased from $22 \%$ in 1984 to $8 \%$ in 2003. The proportion of persons without recorded bone loss increased from $46 \%$ in 1973 to $76 \%$ in 2003 . The oral hygiene improved from 1973 to 1993 with no further improvement during the last decennium.

Conclusion: There has been a positive development in oral health among young, urban adults in Norway during the last 30 years.
\end{abstract}

In the present paper, information from the first author's PhD-thesis (1) is extensively used.

\section{INTRODUCTION}

Dental caries is one of the most prevalent chronic diseases worldwide (2). Just over a half century ago dental caries was considered a major dental health problem, widespread in the Western countries including Norway and causing discomfort, pain and tooth loss across all age groups. During the last decades a substantial reduction in prevalence of dental caries has occurred, especially among children and adolescents, and the changes are well documented (3-5).

"Periodontal diseases" is a non-specific term given to any disease or disease process that affects the periodontium. Most commonly the term refers to the inflammatory periodontal diseases - gingivitis and periodontitis. Periodontitis, or destructive periodontontal disease, is the progressive loss of attachment of the gingival tissues and the subsequent loss of alveolar bone (6). Prevalence and severity of periodontal diseases, together with dental caries, are important indicators when assessing dental health in different populations.

Compared to data on changes in dental caries, there is less evidence for trends in periodontal health. Studies reporting time trends in periodontal diseases indicate improvements in gingivitis and mild/moderate periodontitis without clear indications of reduction in severe forms of periodontitis (7).

Epidemiological data on dental diseases has often been restricted to dental caries and periodontal diseases while information on periapical and endodontic conditions is rather limited. Apical periodontitis is an inflammatory disorder caused by microorganisms colonizing the root canal system. Apical periodontitis usually develops after pulp necrosis, which can occur as a sequel to caries, trauma, periodontal disease or operative procedures (8). A majority of apical periodontitis lesions seem to occur in previously root filled teeth (9-11). Untreated apical periodontitis represents a chronic infection which may remain quiescent but may also become symptomatic or spread with serious consequences for the individual (12). Epidemiological studies indicate that apical periodontitis affects $37-71 \%$ of individuals in different populations and the prevalence is increasing with age (13). Together with dental caries and marginal periodontitis, apical periodontitis can compromise tooth survival.

Dental caries has traditionally been considered as one of the main reasons for pulpal infection. The sub- 
Table 1. Number of participants, response rates and socio-demographic characteristics of participants, 1973-2003.

\begin{tabular}{lccccccc}
\hline & & \multicolumn{2}{c}{ Gender } & & \multicolumn{3}{c}{ Region of birth } \\
\cline { 3 - 4 } \cline { 6 - 7 } $\begin{array}{l}\text { Year of } \\
\text { study }\end{array}$ & $\begin{array}{c}\text { Number of partici- } \\
\text { pants (response rate) }\end{array}$ & Male & Female & & Norway & $\begin{array}{c}\text { Western } \\
\text { countries }\end{array}$ & $\begin{array}{c}\text { Non-Western } \\
\text { countries }\end{array}$ \\
\hline 1973 & $117(66 \%)$ & $60(51 \%)$ & $57(49 \%)$ & & $111(95 \%)$ & $5(4 \%)$ & $1(1 \%)$ \\
1984 & $156(80 \%)$ & $78(50 \%)$ & $78(50 \%)$ & & $136(87 \%)$ & $8(5 \%)$ & $12(8 \%)$ \\
1993 & $121(68 \%)$ & $55(45 \%)$ & $66(55 \%)$ & & $105(87 \%)$ & $7(6 \%)$ & $9(7 \%)$ \\
2003 & $149(64 \%)$ & $89(60 \%)$ & $60(40 \%)$ & & $111(75 \%)$ & $15(10 \%)$ & $23(15 \%)$ \\
\hline
\end{tabular}

stantial decline in dental caries among children and adolescents $(5,14)$ and adults $(15-18)$ in the Western countries has been extensively documented. It could be speculated that, because of this decline in dental caries, improvement in endodontic status is likely to occur.

Despite the increased focus on endodontic epidemiology during the last decades, there are relatively few studies exploring time trends in frequency of root fillings and apical periodontitis. Available studies from Sweden indicate that proportions of endodontically treated teeth and teeth with apical periodontitis seemed to be decreasing $(10,19)$.

Available studies indicate that the observed caries decline is gradually transferred into adult cohorts (20). Recently performed studies in Denmark (21), Sweden (19) and Norway (22) document the gradual improvement in oral health among Scandinavian adults. The present paper will specifically focus on the changes in oral health in 35-year-olds from Oslo, Norway observed in four repetitive cross-sectional studies starting in 1973 (1).

\section{MATERIAL AND METHODS}

The present study is based on four cross-sectional agespecific epidemiological studies performed among randomly selected 35-year-olds in Oslo from 1973 to 2003. Number of participants, response rates and some socio-demographic characteristics of the participants are presented in Table 1.

All the four studies employed simple random sampling and the selected participants were invited to participate by an invitation letter with general information about the study. A declaration of consent was obtained from the participants and the principles stated in the Helsinki declaration has been adhered to. Data collection included self administered questionnaires, clinical and radiographic examination of participants at the Faculty of Dentistry, University of Oslo.

\section{Caries registration}

Dental caries was registered clinically and radiographically at the surface level and recorded as decayed, missing and filled surfaces/teeth (DMFS/DMFT), following the same registration criteria in all the four studies (23). All missing teeth, independent of reason for not being present, were registered as M (missing). The $F$ (filled) component comprised restorations without recurrent caries, including all types of filling materials and crowns and D (decayed teeth/surfaces) included both primary and recurrent caries. Third molars were not included in the registrations.

\section{Registration of endodontic status}

Root filled teeth and teeth with apical periodontitis (AP) were detected from panoramic radiographs $(15 \times 30 \mathrm{~cm}$ HR-E30 (Fuji film), Orthophoss), and intraoral radiographs of the respective teeth were then taken. In the 1984-2003 investigations, the periapical status was evaluated using the periapical index system (PAI) (24).

\section{Periodontal status and oral hygiene assessment}

In 1973 the PTNS-index system was used (25). In the later studies periodontal status was registered based on the CPITN index using a CPITN probe and recording findings from index teeth (26). The participants were then classified according to the highest CPITN score per person.

Orthopantomograms from 83 (71\%) of the participants in 1973, $115(74 \%)$ participants in 1984, 117 (97\%) participants in 1993 and 138 (93\%) in 2003 were available for the assessment of radiographic bone loss. Marginal bone level was assessed with a transparent plastic ruler using light board illumination and a measurement technique as described by Schei (27). Bone loss was considered to be present at sites where the distance from alveolar crest to the cemento-enamel junction (CEJ) exceeded $2 \mathrm{~mm}$ and measured to the nearest $10 \%$. The participants were then categorized according to the highest bone loss score recorded at one or more sites.

Oral hygiene of the participants was assessed by the Simplified Oral Hygiene Index (OHI-S) (28), consisting of two separate components, the Debris Index (DI-S) and the Calculus Index (CI-S).

\section{Reliability}

Clinical registrations were performed by different individual examiners in the four studies. Before the main investigation, calibration sessions regarding the diagnostic criteria for caries and periodontal conditions were performed with the examiner from the first (1973) investigation. In addition, double examinations were performed for assessment of intra-examiner agreement in the 1984-2003 studies $(29,30)$. In 2003 double examination of 738 surfaces in 6 individuals was perfor- 
med in order to control intra-examiner consistency for clinical DMF registration. The kappa value for intraobserver agreement was 0.97 . For periodontal conditions, double examination of 36 sextants in 6 participants was performed and the kappa value for intraobserver agreement was 0.73 .

Evaluation of periapical status in 2003 was made independently by two examiners using standardized examination conditions. One of the examiners did all the registrations in the previous studies. Kappa value for inter-examiner agreement of periapical index values (PAI) for all scored teeth was 0.81 .

The measurements of radiographic bone loss from orthopantomograms were carried out by two different examiners, where examiner one assessed material from 1973-1993 and examiner two assessed the 2003 study. Inter-observer agreement was assessed by duplicate recordings of 10 randomly selected orthopantomograms by both examiners. The kappa value for inter-observer agreement was 0.93 . In addition, intra-observer agreement of the second examiner (2003 study) was assessed by duplicate examination of 12 radiographs. The kappa value for intra-observer agreement was 0.93 .

\section{Statistics}

Both published and unpublished data available from the 1973-93 investigations as SPSS files together with data collected in 2003 constituted the basis for the present study. All data were computerised and treated anonymously. Data analysis included assessment of variable distribution and bivariate analysis using $t$ test and ANOVA for continuous variables with Tukey adjustment for comparisons of more than two groups, and Chi-squared test for categorical variables. Data were analyzed by SPSS statistical program package (SPSS for Windows versions 11.0-16.0, SPSS Inc., Chicago, Ill, USA). The significance level was set at 0.05 .

\section{RESULTS}

\section{Dental caries}

The results of the present study indicate a substantial improvement in dental caries over the 30 -year period (31). Since non-Western immigrants had a significantly lower mean DMFS (16.0) and FS-scores (6.4) compared to the rest of the sample, in 2003 this group was excluded from the comparisons with the previous studies (31). The results demonstrate a gradual decrease in caries prevalence from a mean DMFS-score of 68.2 $(\mathrm{SD}=16.4)$ in 1973 to $26.1(\mathrm{SD}=17.3)$ in 2003 (Figure 1).

The proportion of individuals with no cavities increased from $5 \%$ of the sample in 1973 to $54 \%$ in 2003 (Figure 2). In addition, based on evaluation of bitewing radiographs the fillings present appeared smaller and thereby more tooth-saving (less destructive) compared with those observed in the initial studies.

The 35-year-olds in the 2003 investigation have been exposed to fluoride from an early age, compared to the cohorts investigated earlier. Nevertheless, there were only 2 individuals (2\%) without caries and treatment experience, or $\mathrm{DMFS}=0$. In addition, cumulative frequency distributions of DS and FS scores revealed that a small fraction of individuals that still had a high disease level.

\section{Periodontal health}

Changes in periodontal disease indicators from 1973 to 1984 among 35-year-olds in Oslo were assessed by the Periodontal Treatment Need System (PTNS) (25) and described by Hansen (32). The study reported marked reduction in the prevalence and extent of severe periodontitis (PTNS score C).

The last Oslo study from 2003 indicate that the proportion of persons with CPITN-score 4 (one or more pockets $\geq 6 \mathrm{~mm}$ decreased from $21.8 \%$ in 1984 (CPITN-scores from 1973 are not available) to $8.1 \%$ in 2003 (Figure 3).

The proportion of persons without recorded bone loss increased from $46 \%$ in 1973 to $76 \%$ in 2003 (Figure 4) (33).

The assessment of oral hygiene according to the OHI-S index is presented in Figure 5. When the entire

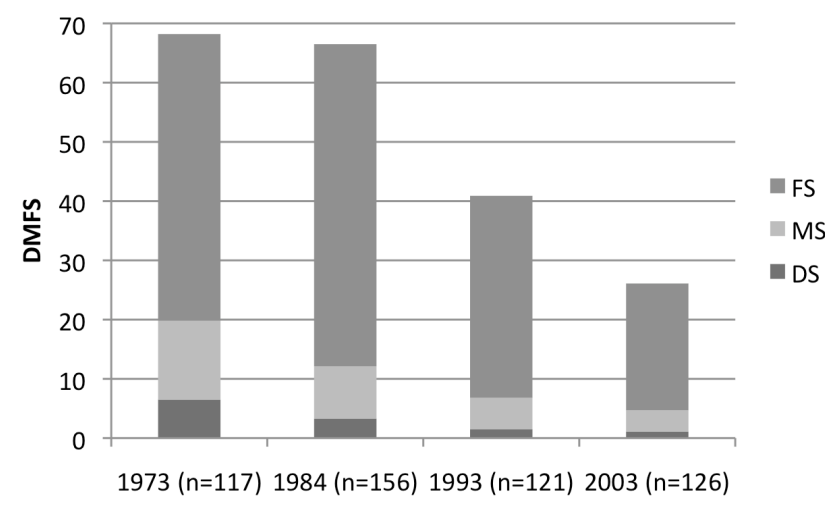

Figure 1. Changes in the mean DMFS scores, 1973-2003 (1).

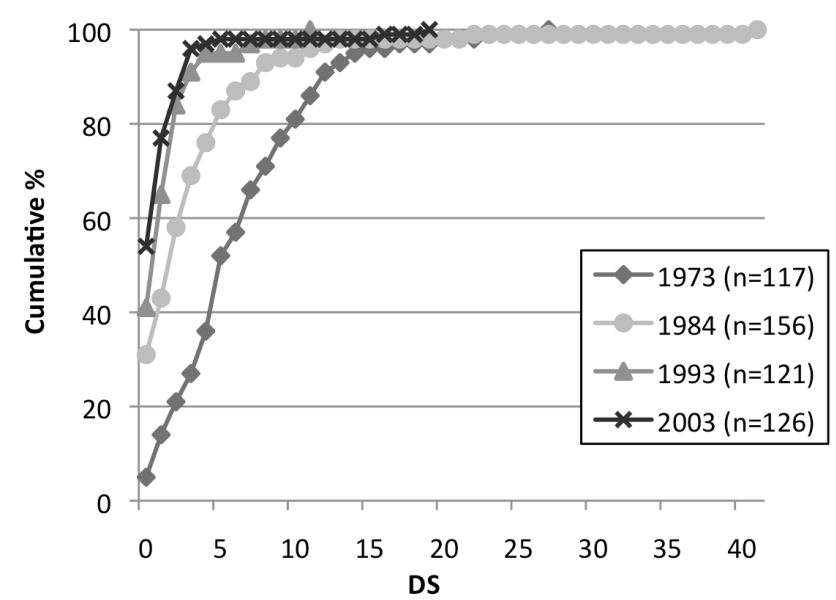

Figure 2. Cumulative frequency distributions of DS scores, according to the year of survey (31). Reprinted with permission from Taylor \& Francis A S. 


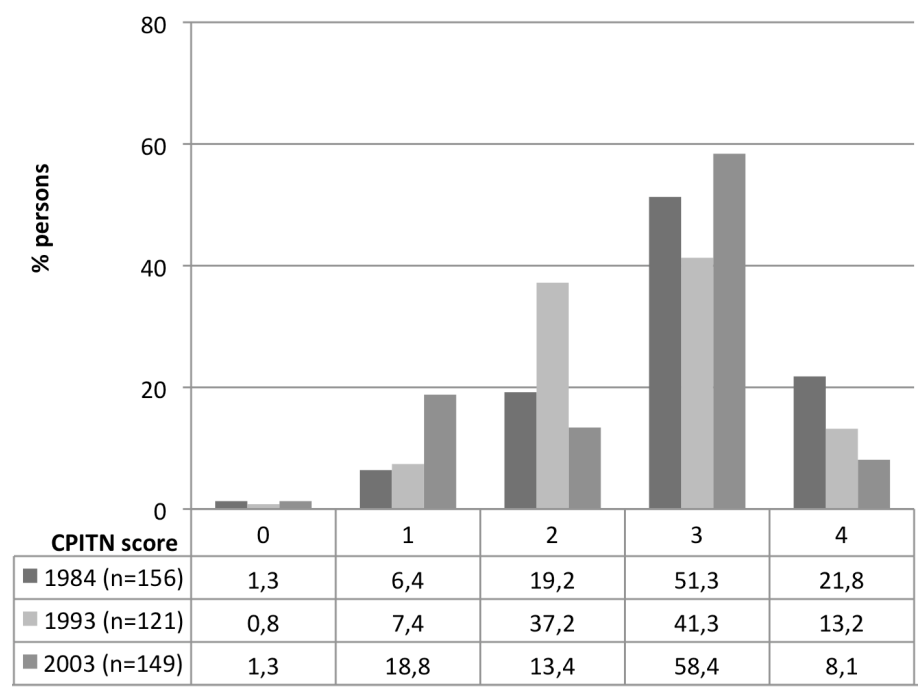

Figure 3. Percentage distributions of participants according to the highest CPITN score per person, 1984-2003 (33). Reprinted with permission from John Wiley and Sons.

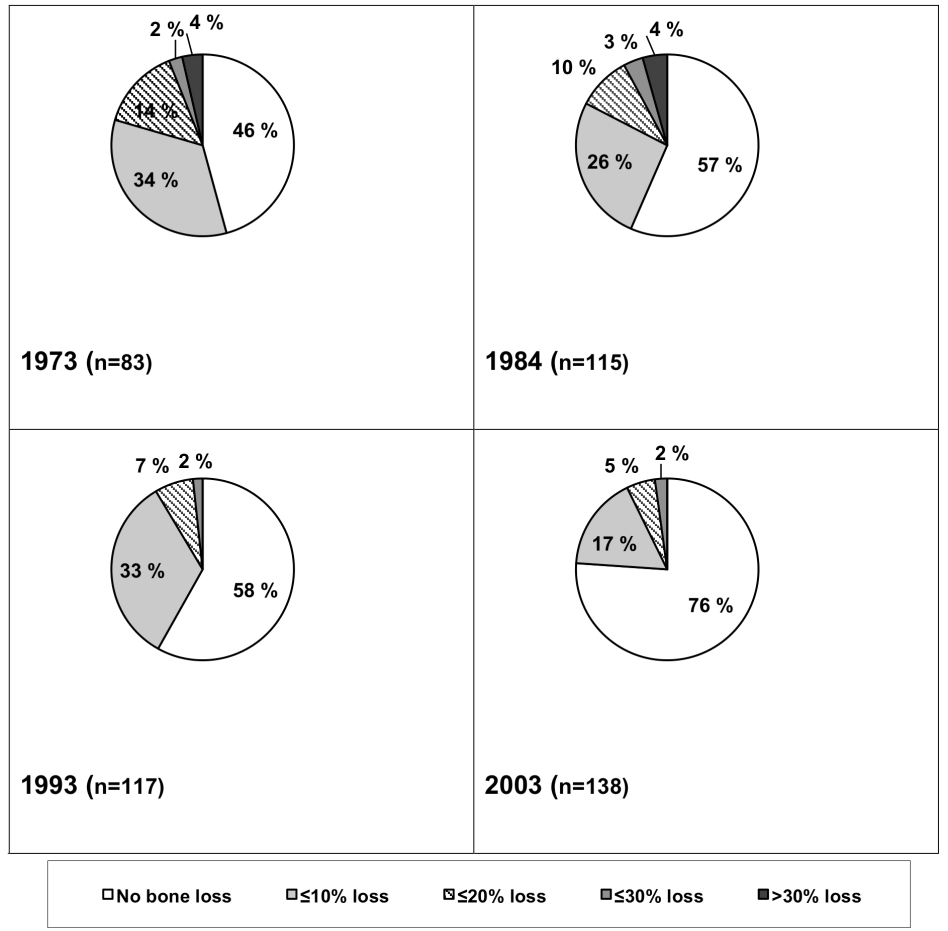

Figure 4. Percentage distribution of participants according to the level of marginal bone loss measured from orthopantomograms in 1973-2003 (33). Reprinted with permission from John Wiley and Sons.

30-year period is considered, there has been a statistically significant reduction in both calculus and plaque scores, indicating that oral hygiene improved substantially. As shown in Figure 5, a shift towards lower OHI-S scores occurred in 1993. Although there was a further decrease in OHI-S score observed between 1993 and 2003, the reduction was minor and not statistically significant.

\section{Endodontic conditions}

The Oslo studies have recorded endodontic conditions in 35-year-olds from 1973 to 2003. A decrease in indi- viduals with root filled teeth from around 50\% in 1973 to $24 \%$ (1993) and $23 \%$ (2003) was found (Figure 6). A concomitant reduction in individuals with apical periodontitis from 30\% (1973) to around 15\% in 1993 and 2003 was observed (34).

\section{Other oral health parameters}

In the series of Oslo studies, other aspects of oral health like mucosal lesions, dental erosions, dental fear and aspects of orally related quality of life have been included, but not in a regular, consecutive manner. They will therefore not be dealt with in this article. 


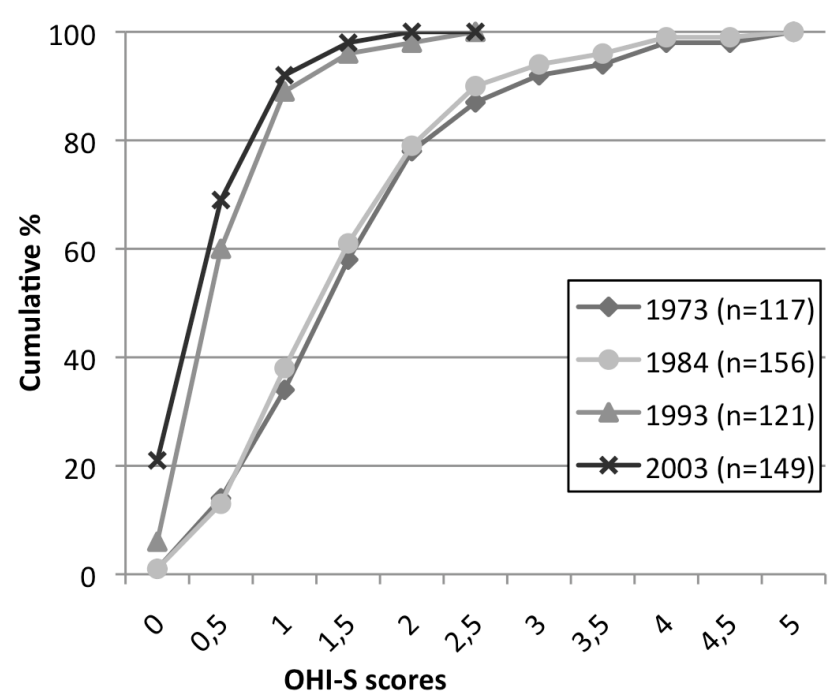

Figure 5. Cumulative percentage distributions of participants according to OHI-S scores, 1973-2003 (33).

Reprinted with permission from John Wiley and Sons.

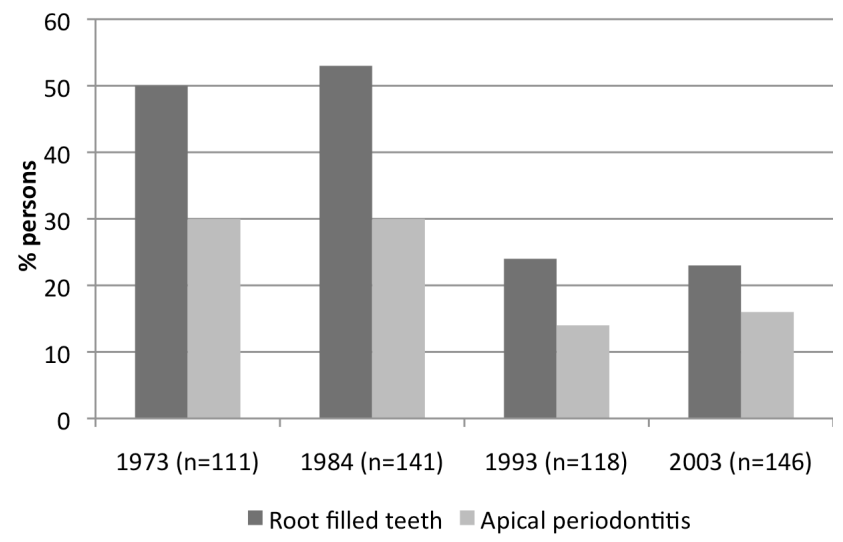

Figure 6. Proportions of individuals with root filled teeth and apical periodontitis, 1973-2003 (1).

\section{DISCUSSION}

The results presented in this article provide documentation on trends the last four decades in dental caries, endodontic and periodontal conditions among 35-yearold urban Norwegians from 1973 to 2003. Ongoing reduction in caries and treatment experience among adults observed in the present study is in agreement with most recent results reported from studies in Norway (22), Sweden (19) and other Western countries $(17,39,40)$. As several of these trend studies report further caries reduction also in younger age groups, it might be reasonable to expect that the observed improvement in caries among adults is going to continue.

The results on endodontic conditions indicate that despite of further caries decline observed during the last decade, prevalence of apical periodontitis and endodontic treatment remained at the same level from 1993 to 2003. A similar trend has been reported by Bjørndal \& Reit in Denmark (41) where no decrease in annual endodontic treatment frequency from 1977 to
2003 has been found despite of reduction in caries. In contrast, studies among adults in Sweden show continuous reduced proportions of root filled teeth for all age groups except 80-year-olds (19). The assessment of periodontal conditions also showed a positive trend, by increased proportion of individuals without marginal bone loss and reduced proportion of individuals with deep pockets. Oral hygiene improvement was observed during the period. The improvement in periodontal conditions observed in the present study is in agreement with results from available investigations on periodontal disease trends (42-44).

Adult dental health status reflects the long-term cumulative impact of prevention and treatment policies. In the report on Future Dental Health Services by the Norwegian Ministry of Health and Care Services, different dental generations have been defined (35). According to this definition, adults born before 1935 belong to the extraction and denture generation, those born from 1935 to 1960 to the filling generation, those born from 1960 to 1990 belong to the fluoride generation and born after 1990 constitute the future generation. Consequently, the first two cohorts investigated in Oslo 1973-1993 studies belong to the filling generation and have received substantial amounts of dental treatment and restorations before fluoride became widely available. The second last study (1993) and particularly the last study includes representatives from the fluoride generation. It is therefore of particular interest to monitor the oral health status of these last groups, indicating what may be expected for future generations.

Efforts have been made to secure reliable and comparable data in the four investigations presented. Calibration sessions and testing of intra- and interexaminer reliability have been regularly performed. Substantial changes in the demographic composition of 35-year-olds in Oslo have occurred during this 30year period. The proportion of non-Western immigrants increased from $1 \%$ in 1973 to $15 \%$ in 2003. Both data from earlier Oslo-studies and the present study showed that caries and treatment experience among nonWestern immigrants was different from the rest of participants. In order to minimize possible effect of demographic composition on time-lag differences in caries, this group was excluded from the comparisons in 2003. The female to male ratios were close to expected in 1973 and 1984 but are 10 percent points higher in 1993 and 20 points higher in 2003. This might have slightly altered the reported trends, as no adjustments have been performed.

The present study was based on random samples of 35 -year-olds and the response rates varied from $64 \%$ to $80 \%$, being lowest in 2003 . Since the detailed information from $53 \%$ of all the non-attenders in 2003 was available, this gave an indication about possible effects of the non-respondents on the results. In addition, data available from Statistics Norway about the general population of 35-year-olds in Oslo gave an indication 
about possible selection bias. Due to the fact that participants with university education and males were overrepresented compared to the general population and also due to the higher proportion of smokers among the non-attenders, there is a possibility that the dental health conditions reported from the 2003 study might be better compared to the general population of 35-year-olds in Oslo.

In 1973 the first epidemiological study on prevalence of dental diseases among 35-year-old Oslo citizens was carried out based on a random sample of 200 individuals (32). Prior to that, information about dental diseases in adults in Norway was fragmentary and based on selected groups of participants $(36,37)$ and representative studies were lacking. The 1973 study provided data on dental diseases in an adult urban population and served as a baseline for future comparisons. Although $89 \%$ of the participants in 1973 visited the dentist regularly at least once a year, the study reported high mean numbers of filled teeth and teeth with untreated decay as well as extensive periodontal treatment need. Five individuals (4\%) were found being edentulous in one jaw (32).

The second cross-sectional study, performed in 1984, reported an improvement in oral health (38). Although the total DMFS score remained high, the number of decayed and missing surfaces decreased and was sub- stituted by increased number of filled surfaces. The proportion of individuals with periodontal pockets deeper than $5 \mathrm{~mm}$ had also decreased from 1973 to 1984 . Both participants in the 1973- and the 1984 studies represented extensively treated adult populations.

When a third study among 35-year-olds in Oslo was performed in 1993, the results indicated marked improvement in oral health compared to 1973 and 1984. The study reported a $38 \%$ reduction in caries prevalence (30) and also an improvement in periodontal conditions.

The last study in the series of repetitive crosssectional assessments performed in 2003 documented further improvement regarding dental caries and periodontal disease, but no improvement in endodontic conditions compared to 1993 (1). The important difference from the cohorts investigated earlier was that the participants (born in 1968) have been exposed to fluorides from an early age.

\section{Conclusions}

The results for the entire 30-year period indicate positive development in oral health among young urban adults in Norway suggesting that the focus on and efforts in dental disease prevention have resulted in substantial reduction of dental diseases among adults.

\section{REFERENCES}

1. Skudutyte-Rysstad R. Studies on dental diseases among 35-year-olds in Oslo, Norway, 1973-2003. Trends and determinants [Thesis]. Oslo, University of Oslo, 2009.

2. Selwitz RH, Ismail AI, Pitts NB. Dental caries. Lancet 2007; 369 (9555): 51-59.

3. Glass RL. The first International Conference on the declining prevalence of dental caries. The evidence and the impact on dental education, dental research, and dental practice. $J$ Dent Res 1982; 61 (spec issue): 13011383.

4. Marthaler TM, O'Mullane DM, Vrbic V. The prevalence of dental caries in Europe 1990-1995 - ORCA Saturday afternoon symposium 1995. Caries Res 1996; 30 (4): 237-255.

5. Marthaler TM. Changes in dental caries 1953-2003. Caries Res 2004; 38 (3): 173-181.

6. World Health Organization. Prevention of oral diseases. Geneva: World Health Organization, 1987.

7. Papapanou PN, Lindhe J. Epidemiology of periodontal diseases. In: Lindhe J, Lang N, Karring TR, eds. Clinical periodontology and implant dentistry, 5 edn. Oxford: Blackwell Munksgaard, 2008: 129-79.

8. Siquieira JF, Jr. Microbiology of apical periodontitis. In: Ørstavik D, Pitt Ford T, eds. Essential endodontology. Prevention and treatment of apical periodontitis, 2nd edn. Oxford: Blackwell Munksgaard, 2008: 135-96.

9. Bergström J, Eliasson S, Ahlberg KF. Periapical status in subjects with regular dental care habits. Community Dent Oral Epidemiol 1987; 15 (4): 236-239.

10. Petersson K. Endodontic status of mandibular premolars and molars in Swedish adults. A repeated crosssectional study in 1974 and in 1985. Endodont Dent Traumatol 1993; 9: 185-190.

11. Kirkevang LL, Hörsted-Bindslev P, Ørstavik D, Wenzel A. Frequency and distribution of endodontically treated teeth and apical periodontitis in an urban Danish population. Int Endodont J 2001; 34 (3): 198-205.

12. Ørstavik D, Pitt Ford T. Apical periodontitis: microbial infection and host responses. In: Ørstavik D, Pitt Ford T, eds. Essential endodontology. Prevention and treatment of apical periodontitis, 2nd edn. Oxford: Blackwell Munksgaard, 2008: 1-9.

13. Eriksen HM. Epidemiology of apical periodontitis. In: Ørstavik D, Pitt Ford T, eds. Essential endodontology. Prevention and treatment of apical periodontitis, 2nd edn. Oxford: Blackwell Munksgaard, 2008: 262-274.

14. von der Fehr FR. Evidence of decreasing caries prevalence in Norway. J Dent Res 1982; 61 (spec issue): 1331-1335. 
15. Downer MC. The improving dental health of United Kingdom adults and prospects for the future. $B r$ Dent $J$ $1991 ; 170$ (4): 154-158.

16. Kalsbeek H, Truin GJ, van Rossum GM, van Rijkom HM, Poorterman JH, Verrips GH. Trends in caries prevalence in Dutch adults between 1983 and 1995. Caries Res 1998; 32 (3): 160-165.

17. Nunn J, Morris J, Pine C, Pitts NB, Bradnock G, Steele J. The condition of teeth in the UK in 1998 and implications for the future. Br Dent J 2000; 189 (12): 639-644.

18. Hugoson A, Koch G, Göthberg C, Helkimo AN, Lundin SA, Norderyd O, et al. Oral health of individuals aged 3-80 years in Jönköping, Sweden during 30 years (1973-2003). I. Review of findings on dental care habits and knowledge of oral health. Swed Dent J 2005; 29 (4): 125-138.

19. Hugoson A, Koch G, Göthberg C, Helkimo AN, Lundin SA, Norderyd O, et al. Oral health of individuals aged 3-80 years in Jönköping, Sweden during 30 years (1973-2003). II. Review of clinical and radiographic findings. Swed Dent J 2005; 29 (4): 139-155.

20. Eriksen HM. Has caries merely been postponed? Acta Odont Scand 1998; 56 (3): 173-175.

21. Petersen PE, Kjøller M, Christensen LB, Krustrup U. Changing dentate status of adults, use of dental health services, and achievement of national dental health goals in Denmark by the year 2000. J Public Health Dent 2004; 64 (3): 127-135.

22. Holst D, Schuller AA, Dahl KE. Bedre tannhelse for alle? Tannhelseutvikling i den voksne befolkning i Nord Trøndelag fra 1973 til 2006. Nor Tannlegeforen Tid 2007; 117 (13): 804-811.

23. World Health Organization. Oral health surveys. Basic methods, 3rd edn. Geneva: World Health Organization, 1987.

24. Ørstavik D, Kerekes K, Eriksen HM. The periapical index: a scoring system for radiographic assessment of apical periodontitis. Endodont Dent Traumatol 1986; 2 (1): 20-34.

25. Johansen JR, Gjermo P, Bellini HT. A system to classify the need for periodontal treatment. Acta Odont Scand 1973; 31 (5): 297-305.

26. Ainamo J, Barmes D, Beagrie G, Cutress T, Martin J, Sardo-Infirri J. Development of the World Health Organization (WHO) community periodontal index of treatment needs (CPITN). Int Dent J 1982; 32 (3): 281 291.

27. Schei O, Wærhaug J, Lovdal A, Arno A. Alveolar bone loss as related to oral hygiene and age. J Periodont 1959; 30: 7-16.

28. Greene JC, Vermillion JR. The simplified oral hygiene index. J Am Dent Assoc 1964; 68: 7-13.

29. Bjertness E, Eriksen HM, Hansen BF. Caries prevalence of 35-year-old Oslo citizens in 1973 and 1984. Community Dent Oral Epidemiol 1986; 14 (5): 277-282.

30. Berset GP, Eriksen HM, Bjertness E, Hansen BF. Caries experience of 35-year-old Oslo residents and changes over a 20-year period. Community Dent Health 1996; 13 (4): 238-244.

31. Skudutyte-Rysstad R, Eriksen HM. Changes in caries experience among 35-year-old Oslo citizens, 19732003. Acta Odontol Scand 2007; 65 (2): 72-77.

32. Hansen BF. Dental conditions in a 35-year-old Norwegian urban population [Thesis]. Oslo, University of Oslo, 1976.

33. Skudutyte-Rysstad R, Eriksen HM, Hansen BF. Trends in periodontal health among 35-year-olds in Oslo, 1973-2003. J Clin Periodont 2007; 34 (10): 867-872.

34. Skudutyte-Rysstad R, Eriksen HM. Endodontic status amongst 35-year-old Oslo citizens and changes over a 30-year period. Int Endod J 2006; 39 (8): 637-642.

35. The Norwegian Ministry of Health and Care Services. St.meld.nr.35. Tilgjengelighet, kompetanse og sosial utjevning. Framtidas tannhelsetjenester. The Norwegian Ministry of Health and Care Services 2006. http:// www.regjeringen.no/pages/1991309/PDFS/STM200620070035000DDDPDFS.pdf [cited 2008 May 14].

36. Helöe LA. Oral health status and treatment needs in a disadvantaged, rural population in Norway. Community Dent Oral Epidemiol 1973; 1 (3): 94-103.

37. Mjör IA. Interpretations of DMF registrations of Norwegian recruits with emphasis on previous treatment experience. Community Dent Oral Epidemiol 1974; 2 (3): 98-103.

38. Bjertness E. A multidimensional study of dental health in urban Norwegian adults [Thesis]. Oslo, University of Oslo, 1990.

39. Beltran-Aguilar ED, Barker LK, Canto MT, Dye BA, Gooch BF, Griffin SO, et al. Surveillance for dental caries, dental sealants, tooth retention, edentulism, and enamel fluorosis - United States, 1988-1994 and 1999-2002. MMW Surveillance Summaries 2005; 54: 1-43.

40. Slade G, Sanders A. Trends in oral health 1987-2006. In: Slade G, Spencer AJ, Roberts-Thomson K, eds. Australia's dental generations: the National Survey of Adult Oral Health 2004-06. 2007. Canberra: Australian Institute of Health and Welfare, 2007: 96-235. Available from: http:/www.arcpoh.adelaide.edu.au/project/ distribution/nsaoh_pdf\%20files/nsaoh_report.pdf. Accessed 14 Feb 2008. 
41. Bjørndal L, Reit C. The annual frequency of root fillings, tooth extractions and pulp-related procedures in Danish adults during 1977-2003. Int Endodont J 2004; 37: 782-788.

42. Ankkuriniemi O, Ainamo J. Dental health and dental treatment needs among recruits of the Finnish Defence Forces, 1919-91. Acta Odont Scand 1997; 55: 192-197.

43. Kalsbeek H, Truin GJ, Poorterman JH, van Rossum GM, van Rijkom HM, Verrips GH. Trends in periodontal status and oral hygiene habits in Dutch adults between 1983 and 1995. Community Dent Oral Epidemiol 2000; 28: 112-118.

44. Hugoson A, Sjödin B, Norderyd O. Trends over 30 years, 1973-2003, in the prevalence and severity of periodontal disease. J Clin Periodont 2008; 35: 405-414. 